\title{
Caracterização Mecânica e Morfológica de Compósitos de Polipropileno e Fibras de Coco Verde: Influência do Teor de Fibra e das Condições de Mistura
}

\author{
Marina H. Ishizaki, Leila L. Y. Visconte \\ Instituto de Macromoléculas Professora Eloisa Mano, UFRJ \\ Cristina R. G. Furtado, Márcia C. A. M. Leite \\ Instituto de Química, UERJ
}

Jean L. Leblanc

Université Pierre \& Marie Curie, France

Resumo: Compósitos de polipropileno com 10, 20 e 30\% em volume de fibra de coco verde foram obtidos em câmara de mistura Haake, tendo como variáveis a temperatura de processamento e a velocidade de cisalhamento. O módulo de flexão e as características morfológicas dos diferentes compósitos obtidos foram avaliados e comparados com o polipropileno puro. Foi observado que a temperatura de $170{ }^{\circ} \mathrm{C}$, a velocidade do rotor de $60 \mathrm{rpm}$ e o teor de fibra de coco verde de $30 \%$ forneceram o melhor desempenho quanto à flexão. Essas observações foram comprovadas pela análise da morfologia.

Palavras-chave: Compósitos, polipropileno, fibra de coco verde.

\section{Mechanical and Morphological Characterization of Polypropylene and Green Coconut Fiber Composites: Influence of Fiber Content and Mixture Conditions}

Abstract: Polypropylene composites containing 10, 20 and 30\% in volume of green coconut fiber were prepared in a Haake chamber at various processing temperatures and shear rates. The flexural modulus and morphological characteristics of the composites were evaluated and compared with pure polypropylene. Optimization experiments indicated that a temperature of $170{ }^{\circ} \mathrm{C}$, shear rate of $60 \mathrm{rpm}$ and green coconut fiber content of $30 \%$ showed the best properties by flexural modulus. These observations were confirmed by a morphology analysis.

Keywords: Composites, polypropylene, green coconut fiber.

\section{Introdução}

A busca por novos materiais visando minimizar os problemas ambientais, tão discutidos nos últimos tempos, tem levado os cientistas a desenvolver compósitos utilizando fibras naturais como cargas reforçantes ${ }^{[1-4]}$. As fibras naturais, além de serem de fontes renováveis, possuem baixo custo quando comparadas com as fibras sintéticas. No caso das fibras de coco, que são rejeitos das indústrias alimentícias de países tropicais, seu aproveitamento gera vantagens também no que diz respeito à diminuição da quantidade do lixo sólido.

A fibra do coco maduro já vem sendo utilizada na agricultura e na indústria. Por sua vez, a fibra da casca do coco verde, que ainda não vem sendo amplamente utilizada, poderá se tornar matéria-prima importante na produção de compósitos poliméricos. A facilidade de produção, baixa densidade e alta disponibilidade são as vantagens apresentadas por esta fibra.
A fibra de coco é uma fibra lignocelulósica obtida do mesocarpo fibroso do coco, fruto do coqueiro (Cocos nucifera) cultivado extensivamente nos trópicos. No Brasil, o consumo da água do coco verde é cada vez maior, principalmente no verão, ao longo de todo o litoral. Esse consumo crescente traz como conseqüência imediata uma grande produção de resíduo sólido formado pelas cascas fibrosas. O estado do Rio de Janeiro, no verão, produz cerca de 12000 t/mês de rejeito de coco, o que torna premente a necessidade de iniciativas que levem em conta a sua utilização. O uso dessas fibras pode levar à produção de materiais de baixo custo, além de contribuir para a diminuição do lixo sólido ${ }^{[5]}$.

Em compósitos polímero-fibra celulósica, a matriz polimérica é responsável pela distribuição da tensão aplicada ao compósito e sua escolha é limitada principalmente pela temperatura necessária ao processamento, já que as fibras lignocelulósicas degradam em temperaturas elevadas.

Autor para correspondência: Cristina R. G. Furtado, Instituto de Química, UERJ, Av. Maracanã 524 - Pavilhão Haroldo Lisboa da Cunha, CEP: 20559-900, Rio de Janeiro, RJ. E-mail: russi@uerj.br 
Desse modo, a temperatura de processamento deve ser tal que permita a obtenção de misturas homogêneas, sem ocorrência de degradação de fibra. Baseado na processabilidade, propriedades mecânicas, disponibilidade e custo, a matriz polimérica mais escolhida é o polipropileno, pois possui baixa densidade, alta rigidez, propriedades mecânicas adequadas e suficiente diversidade de "grades", além de ser facilmente processado devido à sua baixa temperatura de processamento $^{[6]}$. Essas características tornam o polipropileno, principalmente quando reforçado, capaz de competir com plásticos de engenharia de maior custo em várias aplicações.

Este trabalho teve como objetivos o preparo de compósitos de polipropileno reforçados com fibras de coco verde em diferentes proporções e obtidos em diferentes temperaturas de processamento e velocidade de rotação e a avaliação desses compósitos quanto seu módulo de flexão e características morfológicas.

\section{Experimental}

\section{Materiais e métodos}

Todos os materiais foram usados como recebidos. O homopolímero de polipropileno (PP 1074) foi fornecido pela ExxonMobil Chemical, com densidade $0,9 \mathrm{~g} / \mathrm{cm}^{3}$ e MFI $\left(230^{\circ} \mathrm{C} / 2,16 \mathrm{~kg}\right) 20 \mathrm{~g} / 10 \mathrm{~min}$, enquanto que as fibras de coco verde (FCV), resistência à tração de $220 \mathrm{MPa}$ e módulo de 6 $\mathrm{GPa}$, foram doadas pelo Projeto Coco Verde, RJ.

\section{Tratamento e caracterização das fibras de coco}

As fibras de coco verde sofreram processos físicos de moagem e peneiramento manual utilizando peneira de 40 mesh. Em seguida, foram secas em estufa sem circulação de ar, durante 24 horas, a uma temperatura de $80{ }^{\circ} \mathrm{C}$ e, por mais 1 hora, a $110^{\circ} \mathrm{C}$ em estufa com circulação de ar, imediatamente antes do processamento.

As fibras de coco foram analisadas utilizando um microscópio ótico (estereomicroscópio) Olympus, modelo SZH10, para a determinação da largura e do comprimento das fibras de coco usadas. As amostras foram espalhadas sobre uma superfície e fotografadas.

\section{Obtenção dos compósitos}

As misturas foram preparadas na câmara de mistura do reômetro de torque Haake 9000, com rotores do tipo Roller. As misturas foram preparadas durante 8 minutos com velocidades do rotor de 20,40 e 60 rpm e temperaturas da câmara de mistura de 170,180 e $190{ }^{\circ} \mathrm{C}$. Foram preparados compósitos de $\mathrm{PP} /$ fibra de coco verde com teor de carga de 10,20 e $30 \%$ em volume.

\section{Testes de flexão}

Os corpos de prova para os ensaios de flexão foram obtidos de uma placa da amostra, moldada por compressão em prensa Carver à temperatura de $185^{\circ} \mathrm{C}$ sob pressão de $7 \mathrm{MPa}$ durante 2 minutos, seguida de resfriamento sob pressão em prensa com circulação de água. Os corpos-de-prova foram serrados manualmente com as seguintes dimensões $(12,7 \times 130 \times 3) \mathrm{mm}$. Os ensaios foram realizados segundo a norma ASTM D790-92, Método I - Procedimento B, a temperatura de $25^{\circ} \mathrm{C}$ e velocidade de ensaio de $1 \mathrm{~mm} / \mathrm{min}$, com espaçamento entre barras de $50 \mathrm{~mm}$, utilizando o método de três apoios e célula de carga de $1 \mathrm{kN}$. O teste foi interrompido quando se atingiu $5 \%$ de deformação, conforme descrito na norma. $\mathrm{O}$ resultado final consiste de uma média de 10 corpos-de-prova.

\section{Microscopia Eletrônica de Varredura (MEV)}

As amostras contendo PP/fibra de coco verde foram imersas em nitrogênio líquido por alguns minutos e fraturadas manualmente, sendo posteriormente recobertas por uma fina camada de ouro e observadas em Microscópio Eletrônico de Varredura (MEV) JEOL JSL 5300, utilizando voltagem de aceleração do feixe de elétron de $10 \mathrm{kV}$, a fim de se estudar a morfologia.

\section{Resultados e Discussão}

A Figura 1 mostra a curva de distribuição de tamanhos das fibras de coco verde utilizadas. Foi observado que há uma grande quantidade de fibras com tamanho inferior a $1 \mathrm{~mm}$. É observada uma grande heterogeneidade nas dimensões das fibras (Figura 2). Segundo a literatura, a faixa de comprimentos de fibras de coco entre 1-3 cm é considerada ideal para reforço de matrizes poliméricas ${ }^{[7]}$. No presente estudo, o valor médio encontrado para o comprimento da fibra foi inferior ao valor considerado ideal.

As Figuras 3-5 mostram os resultados dos ensaios de flexão das amostras de PP puro e dos compósitos obtidos em diferentes temperaturas, velocidades de rotação e teores de fibras.

\section{Influência do teor de fibra}

$\mathrm{O}$ efeito do teor de fibra no módulo de flexão dos compósitos foi estudado utilizando 10, 20 e 30\% em volume de fibra de coco verde. Por meio dos resultados apresentados é possível observar que, com a adição da fibra, houve um decréscimo no módulo de flexão dos compósitos em relação ao PP puro, seguido de um ligeiro aumento, à medida que a concentração de fibra aumentou, independente da temperatura de mistura. Em baixas concentrações, as fibras presentes na

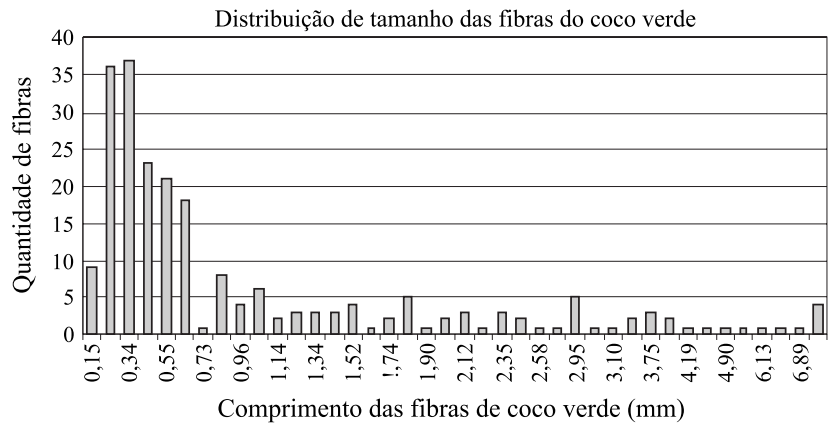

Figura 1. Curva de distribuição de tamanho das fibras do coco verde após peneiramento. 


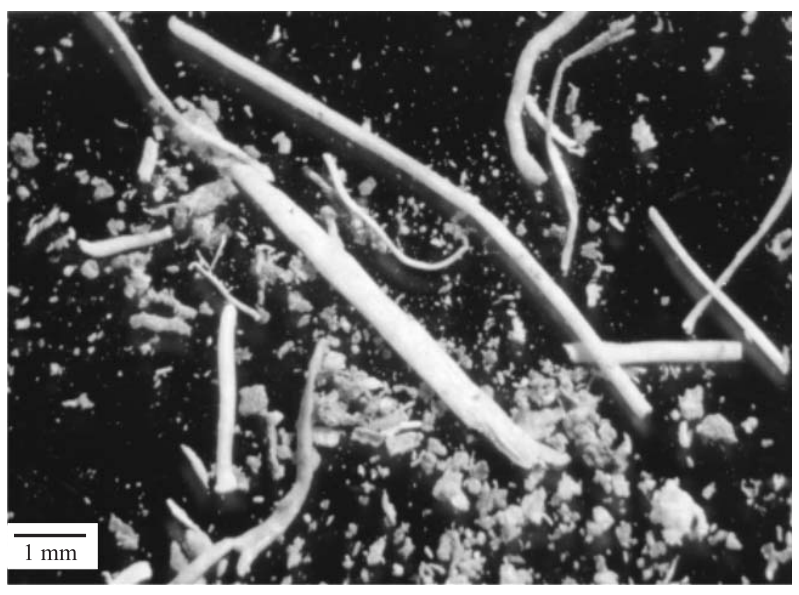

Figura 2. Microscopia ótica das fibras de coco verde usadas nas composições.

matriz polimérica não são suficientes para fornecer uma mistura homogeneamente dispersa, gerando tensões localizadas e ocasionando um menor módulo. Com o aumento do teor de fibra, as tensões são mais bem distribuídas e o material passa a apresentar maior resistência. As misturas contendo $30 \%$ de fibra apresentaram resultados de módulo de flexão próximos ou superiores ao do PP puro.

\section{Influência da velocidade de rotação}

As velocidades de rotação estudadas foram de 20, 40 e 60 rpm. De um modo geral, os melhores resultados encontrados foram a $60 \mathrm{rpm}$, principalmente quando maiores teores de carga foram usados. Tal comportamento evidencia que a homogeneidade da mistura exerce forte influência sobre o módulo de flexão já que quanto maior a rotação, maior também é o cisalhamento, resultando em uma mistura mais homogênea. Porém, esta tendência não foi observada em todas as composições devido provavelmente à não homogeneidade das partículas de carga que, além do material fibroso, apresentava também uma grande parte na forma de pós, como foi observado pela microscopia ótica (Figura 2).

\section{Influência da temperatura}

É bem conhecido da literatura que a temperatura de processamento é um fator extremamente importante para o estabelecimento das condições ótimas de processamento ${ }^{[8]}$. Diante disto, neste trabalho foram empregadas temperaturas de 170,180 e $190^{\circ} \mathrm{C}$. De um modo geral, observando as Figuras 3-5, os melhores resultados do ensaio de flexão foram obtidos na temperatura de $170{ }^{\circ} \mathrm{C}$.

Esse resultado pode parecer contraditório, pois se espera que uma temperatura mais alta permita uma distribuição mais uniforme das fibras na matriz do polipropileno. No entanto, é preciso lembrar que as fibras de coco são muito sensíveis ao calor. Os resultados obtidos mostram que pode ter ocorrido algum processo de degradação da carga levando então, a uma deterioração da propriedade com o aumento da temperatura.

\section{Microscopia Eletrônica de Varredura (MEV)}

A Figura 6 apresenta as fotomicrografias de MEV, com

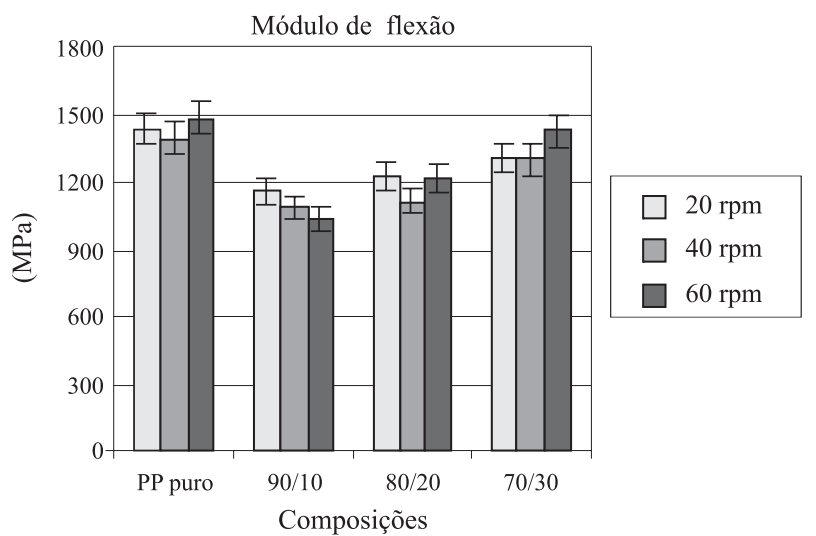

Figura 3. Valores de módulo de flexão para o PP e suas composições com fibra de coco verde em função da velocidade de rotação a $170{ }^{\circ} \mathrm{C}$.

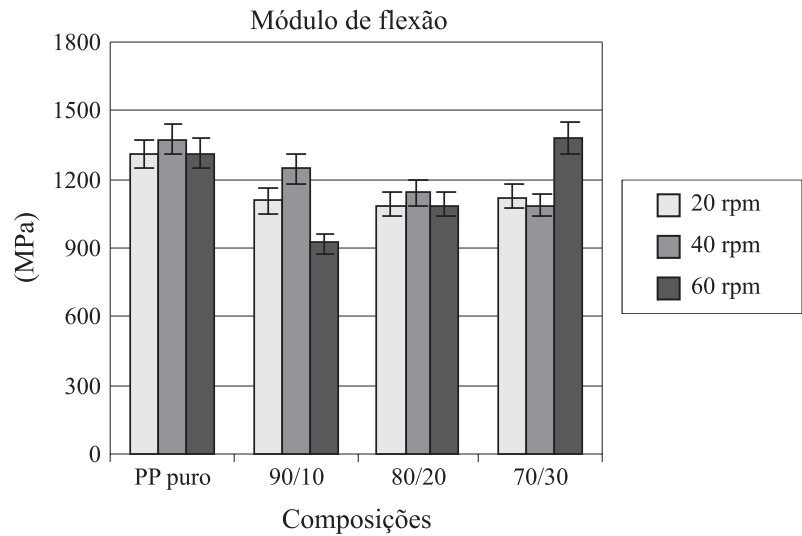

Figura 4. Valores de módulo de flexão para o PP e suas composições com fibra de coco verde em função da velocidade de rotação a $180^{\circ} \mathrm{C}$.

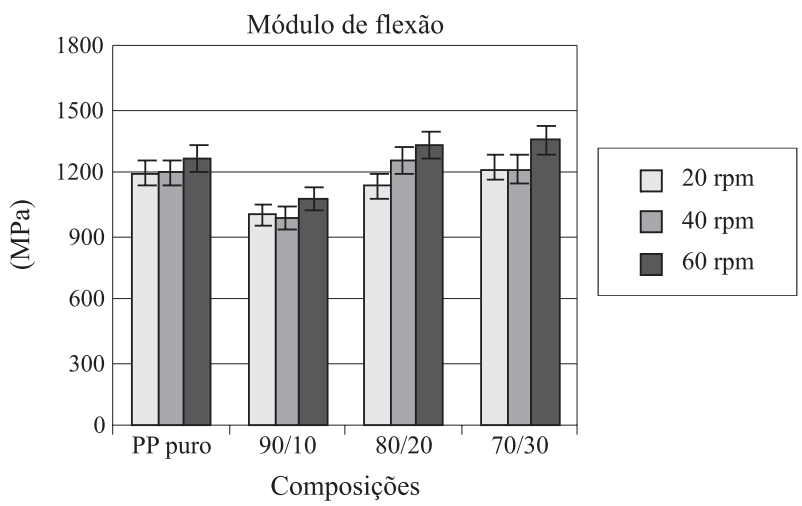

Figura 5. Valores de módulo de flexão para o PP e suas composições com fibra de coco em função da velocidade de rotação a $190{ }^{\circ} \mathrm{C}$.

aumento de 100x, dos compósitos de PP-fibra de coco verde obtidos a $170^{\circ} \mathrm{C}$, com diferentes teores de fibra e em duas velocidades de cisalhamento. Percebe-se, claramente, nas fotomicrografias $(\mathrm{C}-\mathrm{H})$, uma interface bem definida entre a fibra e a matriz polimérica. As fibras encontram-se descoladas da matriz polimérica, conforme indicado pelas setas, sugerindo pouca afinidade entre as fases. Essa morfologia explica a queda do módulo de flexão das composições contendo fibras em relação ao PP puro. Considerando o aumento da velocidade de rotação, a tendência é que ocorra uma melhor homogeneização das misturas. $\mathrm{O}$ aumento da velocidade pode também causar desfibrilação, o que resultaria em maior área 

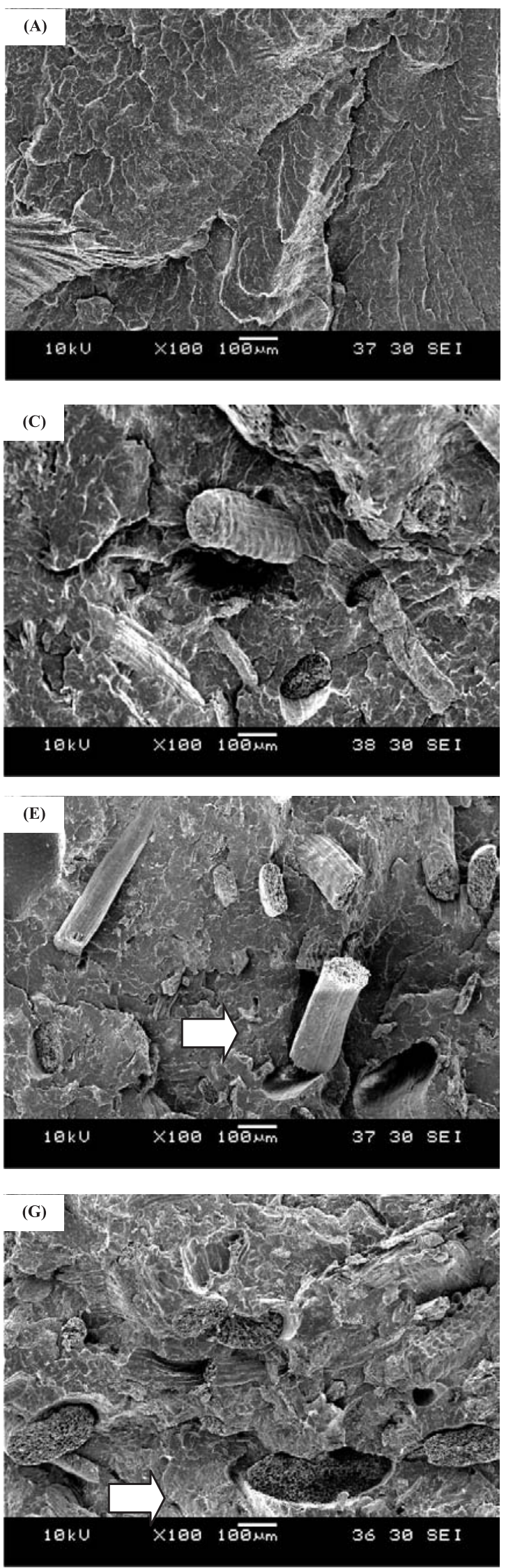
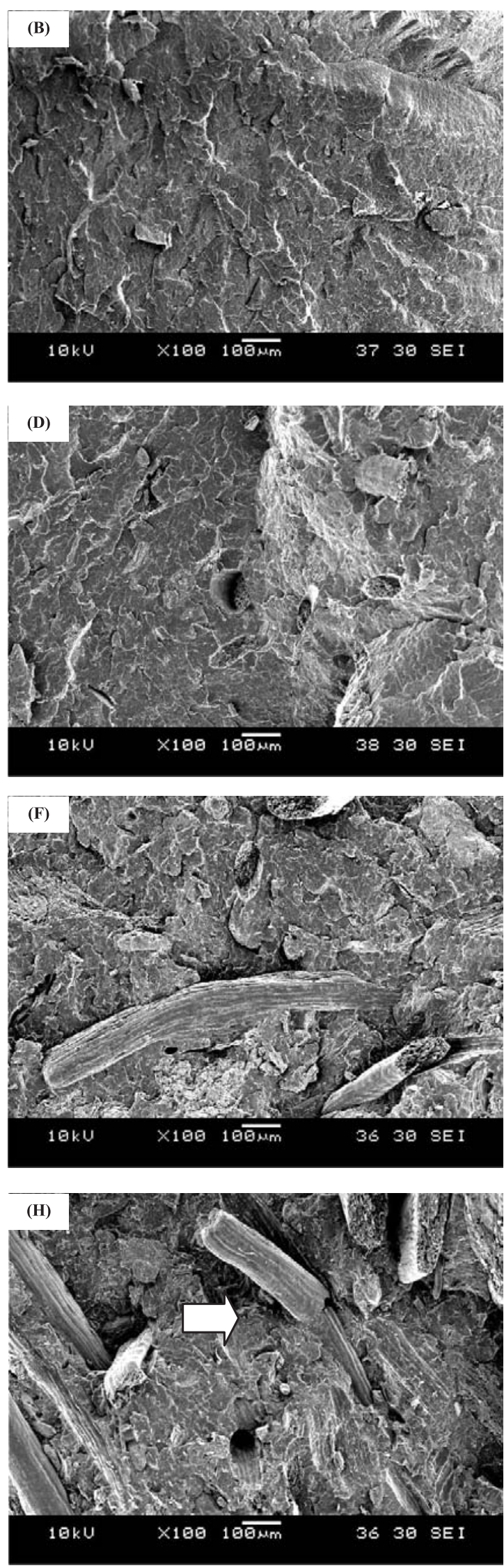

Figura 6. Fotomicrografias de MEV da superfície de fratura dos compósitos PP/fibra de coco verde obtidos a $170{ }^{\circ} \mathrm{C}(100 \mathrm{x})$. (A) 100/0-20rpm; (B) $100 /$ 0-60rpm; (C) 90/10-20rpm; (D) 90/10-60rpm; (E) 80/20-20rpm; (F) 80/20-60rpm; (G) 70/30-20rpm; (H) 70/30-60rpm. 
específica das fibras, favorecendo a adesão na matriz. A velocidade de rotação, no entanto, não deve ser muito elevada, de modo a evitar a quebra das fibras. Nas composições de $\mathrm{PP} /$ fibra de coco verde 90/10 foi observado que o módulo de flexão do composto obtido a $60 \mathrm{rpm}$ foi inferior ao obtido a $20 \mathrm{rpm}$. Observando-se as fotomicrografias C e D é possível perceber que no composto obtido a $60 \mathrm{rpm}$, praticamente não há presença de fibras, quando comparado com o composto obtido a $20 \mathrm{rpm}$. Provavelmente a grande heterogeneidade da carga, já observada pela microscopia ótica nas Figuras $1 \mathrm{e}$ 2 pode ter influenciado nos resultados de módulo de flexão.

\section{Conclusões}

A partir dos resultados obtidos, conclui-se que o uso da câmara de mistura Haake para a obtenção dos compósitos de polipropileno e fibra do coco verde não foi eficiente, já que o desempenho dos compósitos foi semelhante ao polipropileno puro. Dentre as condições de processamento, a temperatura de $170{ }^{\circ} \mathrm{C}$, a velocidade do rotor de $60 \mathrm{rpm}$ e o teor de fibra de coco verde de $30 \%$ forneceram o melhor desempenho quanto a flexão, conforme corroborado pelas análises de microscopia eletrônica de varredura.

\section{Agradecimentos}

Os autores agradecem ao CNPq, CAPES-COFECUB e ao CEPG pelo apoio financeiro e ao Projeto Coco Verde -RJ pela doação das fibras de coco verde.

\section{Referências Bibliográficas}

1. Wambua, P.; Ivens, J.; Verpoest, I. - Composites Science and Technology, 63, p.1259 (2003).

2. Wielage, B.; Lampke, Th.; Marx, G.; Nesther, K., Starke, D. - Thermochimica Acta, 337, p.169 (1999).

3. Singleton, A. C. N.; Baillie, C. A.; Beaumont, P. W. R.; Peijs, T. - Composites: Part B: Engineering, 34, p.519 (2003).

4. Pothan, L. A.; Thomas, S. - Composites Science and Technology, 63, p.1231 (2003).

5. Santos, M. S. "Propriedades térmicas e mecânicas de materiais reciclados à base de PET pós-consumo e cargas de coco", Tese de Mestrado, Universidade Federal do Rio de Janeiro, Brasil (2002).

6. Velde, K. V.; Kiekens, P. - Composite Structures, 54, p. 355 (2001).

7. Junior, H. S. - Revista brasileira de engenharia agrícola e ambiental, 1, p. 103 (2000).

8. Leão, A.; Carvalho, F.; Frollini, E. "Lignocellulosic Plastics Composites", Universidade de São Paulo, Universidade Estadual Paulista, Book Sponsors (1997).

Enviado: 13/12/05

Reenviado: 31/03/06

Aprovado: 07/04/06 